\title{
Ginkgo biloba Seeds-An Environmental Pollutant or a Functional Food
}

\author{
Teodora Tomova $^{1, *(\mathbb{D})}$, Iva Slavova ${ }^{1}\left(\mathbb{D}\right.$, Desislav Tomov $^{2} \mathbb{D}$, Gergana Kirova ${ }^{1}\left(\mathbb{D}\right.$ ) and Mariana D. Argirova ${ }^{1}(\mathbb{D}$ \\ 1 Department of Chemical Sciences, Faculty of Pharmacy, Medical University of Plovdiv, \\ 4000 Plovdiv, Bulgaria; iva.slavova@mu-plovdiv.bg (I.S.); gergana.kirova@mu-plovdiv.bg (G.K.); \\ mariyana.argirova@mu-plovdiv.bg (M.D.A.) \\ 2 Department of Bioorganic Chemistry, Faculty of Pharmacy, Medical University of Plovdiv, \\ 4000 Plovdiv, Bulgaria; desislav.tomov@mu-plovdiv.bg \\ * Correspondence: teodora.tomova@mu-plovdiv.bg
}

Citation: Tomova, T.; Slavova, I.; Tomov, D.; Kirova, G.; Argirova, M.D. Ginkgo biloba Seeds-An

Environmental Pollutant or a

Functional Food. Horticulturae 2021, 7, 218. https://doi.org/10.3390/ horticulturae7080218

Academic Editors: Rosario

Paolo Mauro, Carlo Nicoletto and Leo Sabatino

Received: 20 May 2021

Accepted: 29 July 2021

Published: 2 August 2021

Publisher's Note: MDPI stays neutral with regard to jurisdictional claims in published maps and institutional affiliations.

Copyright: (c) 2021 by the authors. Licensee MDPI, Basel, Switzerland. This article is an open access article distributed under the terms and conditions of the Creative Commons Attribution (CC BY) license (https:// creativecommons.org/licenses/by/ $4.0 /)$.

\begin{abstract}
Ginkgo biloba has been cultivated in Bulgaria since the end of the 19th century. Ividual specimens can be seen in almost every park. Females of the tree are considered contaminants of the landscape because their ripe seeds have a strong odor and are not utilized. We undertook this study to clarify whether ginkgo seeds of local origin can be converted from an unwanted and unused environmental pollutant into a source of beneficial compounds. Various analytical and chromatographic methods were used to quantify the major constituents and ten biologically active compounds in methanol seed extract. The results showed that the seeds are low in proteins (5\%) and fats (1\%); the seeds were also rich in unsaturated fatty acids and tocopherols. About $44 \%$ of nut starch was resistant to in vitro enzymatic hydrolysis. The amount of terpene trilactones in an aqueous-methanol seed extract was significantly higher than the number of flavonoids. Ginkgotoxin and ginkgolic acid were also found. The extract demonstrated weak antimicrobial activity against thirteen microorganisms. This study revealed that seeds of locally grown Ginkgo trees can be used as a source of biologically active substances. The chemical composition show similarity to those of seeds from other geographical areas.
\end{abstract}

Keywords: Ginkgo biloba; trace elements; starch; flavonoids; terpene trilactones; ginkgotoxin; ginkgolik acid; antimicrobial

\section{Introduction}

Ginkgo biloba seeds do not have the popularity of the leaves and leaf extract; the latter is used as multi-target phytochemical drug to improve memory, blood circulation, and to reduce symptoms of psychiatric disorders [1-3]. Ginkgo nuts have been used as a delicious food after cooking or fermentation in several Asian countries for millennia. Although Ginkgo nuts have a longer history than leaves of uses in traditional medicine, including treatment of frequent urination, enuresis, asthmatic response, and lung tuberculosis the chemical composition and pharmacological potential of this natural product have been the subject of more systematic studies in only the last two decades.

While the Ginkgo biloba tree is native to China, and its kernels are used in national cuisine, in Bulgaria, the seeds have not been used as food. The tree has been cultivated since the end of the 19 th century and several varieties are available for landscaping. During the period of 2011-2014, a partial inventory of the available Bulgarian genetic resources of Ginkgo biloba was made in the areas where it is distributed (southern Bulgaria and the Black Sea coast). Data from this study have shown that Plovdiv was the city with the most specimens (182) of this tree [4]. Most of the cultivars were Ginkgo biloba L. and only two specimens-Ginkgo biloba var. laciniata. Only $7.2 \%$ of these plants were female. Due to the unpleasant smell of ripened fleshy seed coats, sometimes female trees have been intentionally uprooted after planting. Most of the female plants investigated in the 
abovementioned study were 40-50 years old; perhaps in the past, no attempts were made to avoid the female plants that create problems in landscape maintenance.

We undertook this study to clarify whether ginkgo seeds of local origin can be converted from an unwanted and unused environmental pollutant into a source of beneficial compounds. Thus, the first objective of the study was to quantify the substances in the seeds to determine their nutritional value and the second, to quantify some secondary metabolites in the seeds that are thought to be responsible for most of the pharmacological properties of ginkgo leaf extracts. These studies may reveal an opportunity to increase the utilization of Ginkgo seeds in Bulgaria, to reduce environmental pollution, and to open new perspectives for local cultivation of this species.

\section{Materials and Methods}

\subsection{Plant Material}

Most of the seeds were collected from a tree located in the yard of the Medical College of the Medical University of Plovdiv (N 42.120501, E 24.751327) in the first half of November 2017-2020. The soft outer skin was removed, and the seeds were washed thoroughly with tap water and air-dried. Then, they were shelled, and the endosperm was homogenized in a high-speed tissue homogenizer and stored in plastic packages at $-20{ }^{\circ} \mathrm{C}$ until use. For comparative studies, seeds from the North (N 42.157510, E 24.732101) and Central (N 42.134982, E 24.733517) regions of Plovdiv were used. In this text, the terms seed, nut, and kernel are used interchangeably.

Dry matter of the seeds was determined gravimetrically, according to European Pharmacopeia 9.6, by heating at $105^{\circ} \mathrm{C}$ to constant weight. The average value of two parallel samples was used when needed.

\subsection{Reagents and Instruments}

All reagents and chromatographic reference compounds used in these experiments were obtained from Merck-Sigma-Aldrich (Germany) and were of the highest purity available. Solvents used for chromatographic analyses were of LC-MS grade. Deionized water $\left(18.2 \mathrm{~m} \Omega / \mathrm{cm}^{2}\right)$ was used thoroughly. Spectronic Camspec M550 (Spectronic Camspec Ltd., Garforth, Leeds, UK) spectrophotometer was used for absorbance readings.

\subsection{Micro Elemental Analysis}

Before analysis, plant material was dried at $105^{\circ} \mathrm{C}$ to constant weight. After grinding in a glass mortar and sieving through a polyamide sieve, the powder obtained was subjected to microwave digestion (Multiwave Go, Anton-Paar, Ashland, VA 23005, USA). One hundred $\mathrm{mg}$ of the sample was mineralized with $2 \mathrm{~mL}$ of conc. $\mathrm{HNO}_{3}$ and $1 \mathrm{~mL}$ deionized water at $190^{\circ} \mathrm{C}$. The following oven program was used: ramp for $20 \mathrm{~min}$, hold for $20 \mathrm{~min}$, and cool for $10 \mathrm{~min}$. Thereafter, the samples were brought up to $30 \mathrm{~mL}$ with water and analyzed by inductively coupled plasma mass spectrometry (ICP-MS) (Thermo Fisher Scientific, Waltham, MA 02451, USA, iCAPQ) in kinetic energy discrimination (KED) mode using 103Rh as an internal standard. Reference material NCS DC 73348 was analyzed in parallel for evaluating the accuracy of the digestion process. Standard multi-element acid solutions were used for calibration and accurate quantitative analysis.

\subsection{Fat and Protein Analyses}

The method approved by the American Oil Chemists Society [5] was used for protein quantification. Fat content was determined according to ISO 659, 2009 [6]. Fatty acids profile was analyzed according to ISO 5509, 2000 and ISO 5508, $2004[7,8]$ using HP 5890 gas chromatography system with flame ionization detector, capillary column Supelco SPTM $2390(30 \mathrm{~m} \times 0.25 \mathrm{~mm})$, and carrier gas $\mathrm{H}_{2}(20 \mathrm{~mL} / \mathrm{min})$. Injector and detector temperature was set at $250{ }^{\circ} \mathrm{C}$; the column temperature program was as follows: $70{ }^{\circ} \mathrm{C}$ (1 min), increase to $190{ }^{\circ} \mathrm{C}$ with a rate $6{ }^{\circ} \mathrm{C} / \mathrm{min}$, then increase to $250{ }^{\circ} \mathrm{C}$ with a rate 
$10^{\circ} \mathrm{C} / \mathrm{min}$. Individual fatty acids were identified and quantified based on the retention times of reference compounds and their peak areas.

Determination of tocopherols in kernel oil was performed by high-performance liquid chromatography (Merck-Hitachi, Darmstadt, Germany) and detected by emission at $330 \mathrm{~nm}$ and excitation at $290 \mathrm{~nm}$ with a fluorescent detector according to ISO 9936, 2006 [9]. Separation was carried out on Nucleosyl Si 50-5 column $(25 \times 0.4 \mathrm{~cm})$ and mobile phase hexane: dioxane $(96: 4, v / v)$ delivered with rate $1.5 \mathrm{~mL} / \mathrm{min}$ and pressure $50 \mathrm{bar}$. The volume of the standard solution injected (mixture of pure $\alpha-, \beta-, \gamma$ - and $\delta$-tocopherols with exact concentrations) was $20 \mu \mathrm{L}$. Individual tocopherols in Ginkgo seed oil were identified and quantified based on the retention times of standards and peak area, respectively.

\subsection{Analyses of Ginkgo Starch}

The residue $(10 \mathrm{~g})$ obtained after triple extraction of seeds with $70 \%$ methanol was homogenized in deionized water $(100 \mathrm{~mL})$ using a laboratory blender at full speed for $4 \mathrm{~min}$. The slurry was filtered successively through a sieve $(0.25 \mathrm{~cm})$ to remove the fiber fraction and a nylon screen $(150 \mu \mathrm{m})$ to obtain homogeneous starch particle size. After triple washing with water followed by centrifugation at $6000 \times g$ for $20 \mathrm{~min}$ the pellet was collected and dried at $40^{\circ} \mathrm{C}$ for $12 \mathrm{~h}$. The dried starch was ground, passed through a nylon screen, and extracted in Soxhlet apparatus with 75\% 1-propanol for $4 \mathrm{~h}$. The cellulose capsule was then air-dried for $12 \mathrm{~h}$; defatted starch was transferred to a Petri dish and dried for an additional $24 \mathrm{~h}$ at $30^{\circ} \mathrm{C}$. For comparative studies, commercial wheat and maize starch samples obtained from local vendors were sieved through the same size nylon screen and used further without any treatment.

Nicolet iS10 instrument fitted with Smart iTR ${ }^{\mathrm{TM}}$ Attenuated Total Reflectance (ATR) Sampling Accessory with a diamond crystal (Thermo Fisher Scientific, Waltham, MA 02451, USA) was used to collect infrared spectra of the starch samples; 128 scans were applied at resolution $4 \mathrm{~cm}^{-1}$.

Amylose content of the samples was measured according to the iodine binding method [10]. Amylose from potato was used for the calibration plot.

Differential scanning calorimeter B DSC Q200 (TA Instruments, New Castle, DE 19720, USA) was used to study phase transformations of Ginkgo starch; calibration of the instrument was done using indium as a standard and the results were processed with specialized software Universal V4.1D, TA Instruments. Samples (5-10 mg) were moistened with water in an aluminum dish keeping a ratio of 30\% starch (dry matter) and $70 \%$ water. The dish was sealed and left at room temperature for at least $30 \mathrm{~min}$ before analysis. The heating was performed at a linear rate of $10^{\circ} \mathrm{C} / \mathrm{min}$. During the analysis, the weight of the analyzed sample was continuously compared to the weight of an empty aluminum dish.

The rate of in vitro starch hydrolysis was analyzed using K-DSTRS kit (Megazyme, Ireland) according to the manufacturer's assay procedure, and calculations were done using Mega-Calc ${ }^{\mathrm{TM}}$ program. Briefly, starch samples were enzymatically hydrolyzed with pancreatic $\alpha$-amylase and amyloglucosidase at $\mathrm{pH} 6.0$ and $37^{\circ} \mathrm{C}$ with continuous stirring. Aliquots were taken at $20 \mathrm{~min}$ to measure rapidly digestible starch (RDS), at $120 \mathrm{~min}$ to measure slow digestible starch (SDS), and at $240 \mathrm{~min}$ to measure total digestible starch (TDS). Another aliquot was taken after 240-min incubation and subjected to enzymatic hydrolysis with amyloglucosidase to measure resistant starch (RS).

\subsection{Analyses of Secondary Metabolites in Ginkgo Seeds}

Low molecular mass secondary metabolites were extracted from Ginkgo kernels by stirring plant material with 70\% methanol $(1: 10 w / v)$ for $24 \mathrm{~h}$ in dark. After centrifugation and filtration, the insoluble residue was processed in the same way two more times. Dry matter of the combined aqueous-methanolic extracts was determined gravimetrically prior to further analyses.

Total phenol content and flavonoid content of the extracts obtained were determined as described elsewhere [11]. Tannins were quantified according to the protein precipitation 
method [12]. Total carbohydrate content was determined using the anthrone/sulfuric acid method [13]. Qualitative and quantitative determination of phenolic acids was performed using HPLC chromatography with UV detection, as previously reported [14].

Analyses of flavonoids (free aglycones), terpenes, and ginkgotoxin were carried out by LC-MS as previously described [15]. Quantification of ginkolic acid was performed on LCMS (Thermo Dionex Ultimate 3000 chromatographic system and a Thermo TSQ Quantum Access MAX triple quadrupole mass detector with a Heated Electrospray Ionization ionizer) using Syncronis C18 column $(150 \times 4.6,5 \mu \mathrm{m})$ in gradient mode with mobile phases A: $0.1 \%$ formic acid in acetonitrile and B: $0.1 \%$ formic acid in acetonitrile-water $(10: 90, v / v)$ at a flow rate $1 \mathrm{~mL} / \mathrm{min}$. Transition $319.2 \rightarrow 275.3$ was observed at collision energy $23 \mathrm{~V}$. Ginkgolic acid C13:0 was used as a standard.

\subsection{Antimicrobial Analysis}

Twenty microorganisms including seven Gram-positive bacteria, six Gram-negative bacteria, two yeasts, and five fungi strains from the collection of the Department of Microbiology at the University of Food Technologies, Plovdiv, Bulgaria, were selected for antimicrobial tests. Antimicrobial activity of methanol extracts obtained from Ginkgo biloba seeds was determined using the standard agar well diffusion method in Luria-Bertani glucose agar medium (LBG agar medium) as previously described [16]. Methanol was used as a control.

The test bacteria (except for Bacillus subtilis, B. cereus, B. amyloliquefaciens, Micrococcus luteus and yeast Saccharomyces cerevisiae) were cultured on LBG agar medium at $30^{\circ} \mathrm{C}$ for $24 \mathrm{~h}$. The other pathogenic bacteria and yeast Candida albicans were cultured on LBG agar medium at $37^{\circ} \mathrm{C}$ for $24 \mathrm{~h}$. The test fungi were grown on malt extract agar (MEA) at $28^{\circ} \mathrm{C}$ for 7 days or until sporulation.

Ginkgo biloba extract and control were pipetted in a quantity of $60 \mu \mathrm{L}$ into the agar wells $(\mathrm{d}=6 \mathrm{~mm})$ in triplicates. The inoculated Petri dishes were incubated as shown above. Antimicrobial activity was determined by recording the diameter of the inhibition zones around the wells on the 24th and 48th $\mathrm{h}$ of incubation.

Minimum inhibitory concentration (MIC) was determined applying serial dilution technique-a series of two-fold dilutions of the extracts, ranging from $3.5 \mathrm{mg} / \mathrm{mL}$ to $0.014 \mathrm{mg} / \mathrm{mL}$. The samples were pipetted in a quantity of $60 \mu \mathrm{L}$ per well in a preliminarily inoculated with the test microorganisms LBG agar media. The Petri dishes were incubated at the conditions described above. The MIC values were defined as the lowest concentration of the extracts inhibiting completely the growth of each test microorganism around the agar well.

\section{Results}

\subsection{Microelements in Ginkgo biloba Seeds}

Different harvests of Ginkgo biloba kernels were analyzed for the presence of important trace elements-iron, copper, zinc, and selenium. The highest variation was found for iron: between 18 and 64 ppm, copper was in the range 6.5-11.4 ppm, and zinc was 8.8-24 ppm; the amount of selenium in all analyzed samples was below $30 \mathrm{ppb}$ (Table 1).

Table 1. Microelement content of different Ginkgo biloba seed samples. The results are mean of four scans \pm standard deviation (SD).

\begin{tabular}{ccccc}
\hline Sample & Year of Collection & Fe, ppm & Cu, ppm & Zn, ppm \\
\hline North region & 2013 & $29.5 \pm 0.2$ & $7.5 \pm 0.1$ & $8.8 \pm 0.2$ \\
& 2014 & $23.8 \pm 0.2$ & $9.3 \pm 0.4$ & $23.7 \pm 0.5$ \\
& 2015 & $31.4 \pm 1.2$ & $9.0 \pm 0.6$ & $16.7 \pm 1.1$ \\
Central region & 2016 & $64.4 \pm 2.2$ & $11.4 \pm 0.3$ & $20.4 \pm 0.8$ \\
Medical college & 2017 & $41.8 \pm 0.8$ & $9.67 \pm 0.2$ & $24.07 \pm 0.9$ \\
(South region) & & & & \\
& 2017 & $18.3 \pm 0.2$ & $6.5 \pm 0.2$ & $13.5 \pm 0.05$ \\
\hline
\end{tabular}




\subsection{Proteins and Lipids in Ginkgo biloba Seeds}

The protein content determined by the Kjeldahl method was $5 \%$ of the raw seed weight or about $11 \%$ of the dry matter and comparable to the data summarized in [17].

The lipid content of raw Ginkgo biloba nuts was 1\% (2.04\% dry weight basis). Individual fatty acids quantified as methyl esters by gas-chromatography are shown in Table 2.

Table 2. Fatty acid composition of triacylglycerides obtained from Ginkgo biloba nuts (crop 2019).

\begin{tabular}{|c|c|}
\hline Fatty Acids & $\%$ \\
\hline $\mathrm{C} 10: 0$ & 0.1 \\
\hline C12:0 & 0.1 \\
\hline C14:0 & 0.6 \\
\hline C14:1 & 0.5 \\
\hline C15:0 & 0.4 \\
\hline C16:0 & 14.9 \\
\hline C16:1 & 3.5 \\
\hline C17:0 & 0.2 \\
\hline C17:1 & 0.3 \\
\hline $\mathrm{C} 18: 0$ & 2.0 \\
\hline C18:1 & 24.5 \\
\hline $\mathrm{C} 18: 1$ trans & 11.6 \\
\hline C18:2 ( $\omega-6)$ & 32.2 \\
\hline C18:2 trans & 1.8 \\
\hline $\mathrm{C} 18: 3(\omega-3)$ & 0.9 \\
\hline C20:0 & 0.5 \\
\hline C20:1 & 0.3 \\
\hline C20:2 (w-6) & 0.3 \\
\hline $\mathrm{C} 20: 3(\omega-3)$ & 3.4 \\
\hline C20:4 (w-6) & 1.3 \\
\hline C22:0 & 0.1 \\
\hline C22:1 & 0.1 \\
\hline C22:2 ( $\omega-6)$ & 0.2 \\
\hline $\mathrm{C} 20: 5(\omega-3)$ & 0.2 \\
\hline C20:1 & 0.3 \\
\hline C20:2 ( $\omega-6)$ & 0.3 \\
\hline$C 20: 3(\omega-3)$ & 3.4 \\
\hline C20:4 ( $\omega-6)$ & 1.3 \\
\hline C22:0 & 0.1 \\
\hline C22:1 & 0.1 \\
\hline $\mathrm{C} 22: 2(\omega-6)$ & 0.2 \\
\hline $\mathrm{C} 20: 5(\omega-3)$ & 0.2 \\
\hline $\mathrm{C} 20: 3(\omega-3)$ & 3.4 \\
\hline
\end{tabular}

Figure 1a shows the ratio between saturated, monounsaturated, and polyunsaturated fatty acids with different nutritional values.

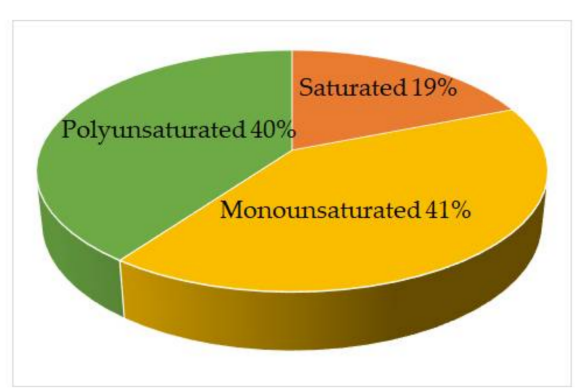

(a)

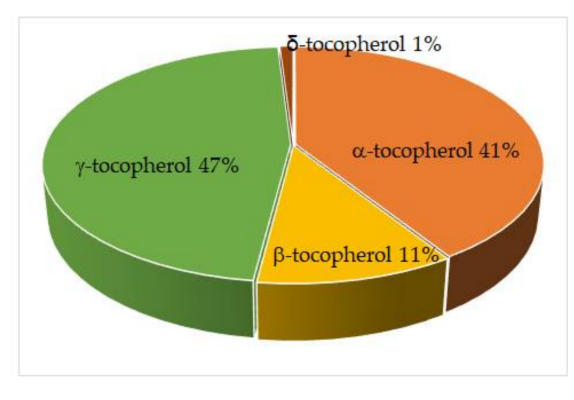

(b)

Figure 1. Lipid constituents of Ginkgo biloba nuts (crop 2019): (a) Relative part of saturated, monounsaturated, and polyunsaturated fatty acids in oil; (b) Individual tocopherol composition.

The total amount of tocopherols was $192.6 \mathrm{mg} / 100 \mathrm{~g}$ oil. Chromatographic quantification of the individual tocopherols showed that, as with most nuts, $\gamma$ - and $\alpha$-tocopherol dominated and were approximately equally represented (Figure $1 b$ ). 


\subsection{Properties of Ginkgo Starch}

The starch was isolated as water-insoluble residue of seeds after extraction with organic solvents and water. The average yield of product after extraction with $70 \%$ methanol and $70 \%$ propanol was about $70 \%$ of the Ginkgo seeds dry matter.

The product obtained was identified as starch by recording its infrared spectrum with attenuated total reflection (FTIR-ATR) (Figure 2). The characteristic bands for $\mathrm{O}-\mathrm{H}$ and $\mathrm{C}-\mathrm{H}$ oscillations can be seen at 3340 and $2930 \mathrm{~cm}^{-1}$, respectively; the triad between 1000 and $1150 \mathrm{~cm}^{-1}$ is characteristic for $\mathrm{C}-\mathrm{O}, \mathrm{C}-\mathrm{C}$ stretching, and $\mathrm{C}-\mathrm{O}-\mathrm{H}$ bending. Spectra of maize and wheat starch were identical; differences that were more significant were observed in the $1550-1750 \mathrm{~cm}^{-1}$ region, which are probably due to the presence of minor components bound to starch (proteins, phosphate esters, etc.).

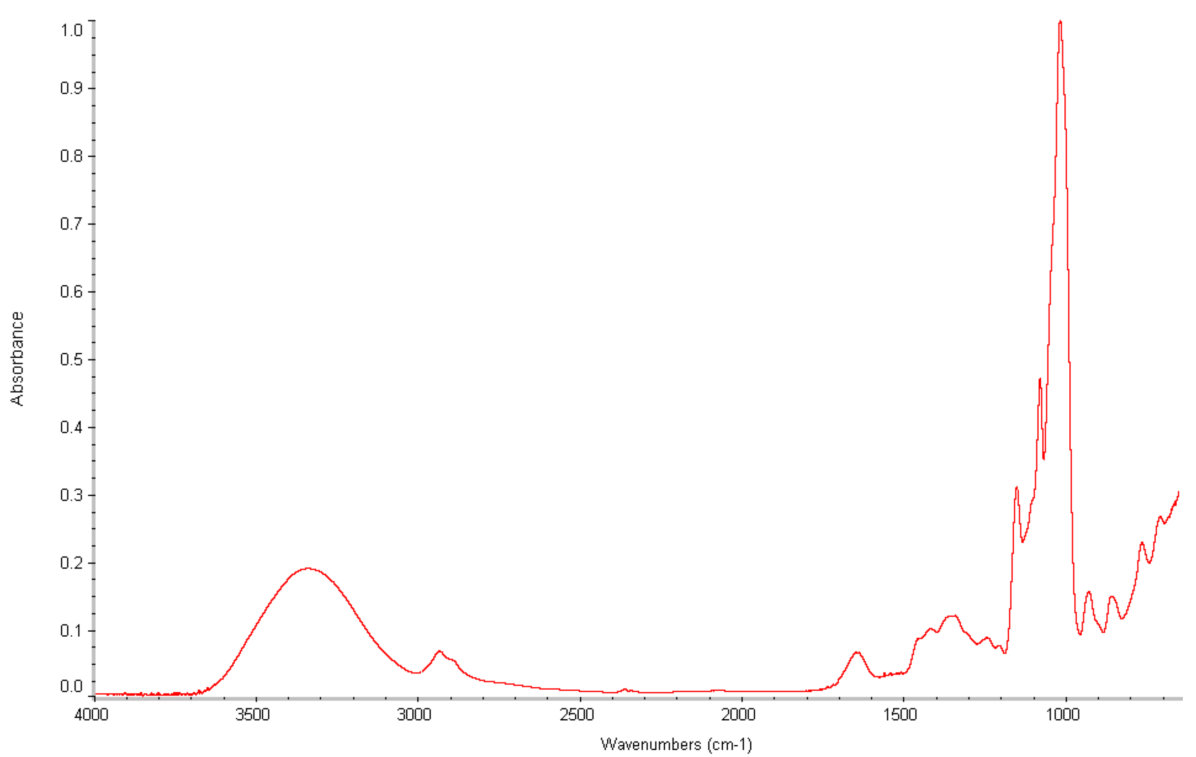

Figure 2. FTIR-ATR spectrum of Ginkgo biloba starch.

The percentage of amylose fraction was highest in Ginkgo biloba starch: $36.9 \pm 5.0$ compared to maize: $23.6 \pm 4.3$ and wheat starch: $22.2 \pm 4.8$ (data are means \pm standard deviation of three parallel samples). The phase transitions in Ginkgo biloba starch begun at about $62{ }^{\circ} \mathrm{C}\left(\mathrm{T}_{0}\right)$, reached their maximum at $79.5{ }^{\circ} \mathrm{C}\left(\mathrm{T}_{\mathrm{p}}\right)$, which is assumed gelling temperature, and the final transition temperature was $90^{\circ} \mathrm{C}\left(\mathrm{T}_{\mathrm{c}}\right)$. The change in enthalpy determined by instrumental software was $833.1 \mathrm{~J} / \mathrm{g}$. For comparison, the parameters of wheat and maize starches $\left(\mathrm{T}_{0}, \mathrm{~T}_{\mathrm{p}}\right.$ and $\left.\mathrm{T}_{\mathrm{c}}\right)$ transitions were very close to those of Ginkgo biloba starch but the changes in enthalpy were $20-23 \%$ lower.

In vitro kinetic study on Ginkgo starch digestion was based on the presumption that the average time of residence of food in the human small intestine is $4 \pm 1 \mathrm{~h}$. Ginkgo starch demonstrated a lower digestion rate and a higher percentage of resistible starch compared to the types found in Bulgaria wheat and maize starch (Table 3).

Table 3. Rate of in vitro enzymatic hydrolysis of four types of starch. RDS—rapid digestible starch; SDS—slow digestible starch, TDS—-total digestible starch, RS—resistible starch.

\begin{tabular}{cccccc}
\hline Starch & RDS & SDS & TDS & RS & Total Starch \\
\hline Ginkgo biloba (crop 2019) & 7.3 & 26.3 & 42.1 & 33.4 & 75.5 \\
Wheat & 26.3 & 43.0 & 67.1 & 1.7 & 68.8 \\
Maize & 12.17 & 55.1 & 71.9 & 0.8 & 72.7 \\
Standard (manufacturer's & 6.9 & 16.2 & 35.9 & 47.4 & 83.3 \\
data) & 6.0 & 16.8 & 32.8 & 48.9 & 81.7 \\
\hline Standard (values found) & & &
\end{tabular}




\subsection{Secondary Metabolites in Ginkgo Kernels}

Organic extracts containing low molecular mass compounds from Ginkgo seeds were obtained from four crops: 2017-2020. Typically, the yield of dry matter in the methanol extract obtained by cold maceration was $5-8 \%$ of seeds dry matter. Although the extraction procedure was standardized, spectrophotometric and chromatographic methods showed some variation in the content of the major classes of secondary metabolites with, in some cases, concentrations below the limit of detection. Preliminary phytochemical screening of the extracts showed the presence of phenolic compounds (26.4-118 gallic acid equivalents/g dry matter) including flavonoids (from not detectable to 20.0 quercetin equivalents/g) and tannins (1.9-9.4 tannic acid equivalents/g). The extracts also contained carbohydrates (426-716 glucose equivalents/g).

The extracts were further analyzed for some individual bioactive compounds. Among the 10 typically found in plants-hydroxybenzoic and hydroxycinnamic acids (gallic acid, 3,4-dihydroxy benzoic acid, chlorogenic acid, caffeic acid, ferulic acid, p-coumaric acid, sinapic acid, rosmarinic acid, chicoric acid, and cinnamic acid)—only p-coumaric acid was detected at level $0.478 \mathrm{mg} / \mathrm{g}$ dry matter.

Ten other phytochemicals typical for the Ginkgo biloba species were quantified. Variations in the content of flavonoids (quantified as aglycones), terpene trilactones, ginkgotoxin, and ginkgolic acid are shown in Table 4. The selection of reference compounds was based on the mass-spectral studies of Zhou et al. [18], results of which are also included for comparison in Table 4. Recently, data about chemical constituents in plant material (leaves, seed coats, and embryoids) collected from Ginkgo trees aged between 25 and 2000 years have been reported [19], also shown in Table 4.

Table 4. Amounts of bioactive compounds in Ginkgo biloba seed extracts. The results are presented in $\mu \mathrm{g} / \mathrm{g}$ of dry extract.

\begin{tabular}{cccc}
\hline Compound & Own Results & {$[18]$} & {$[19]$} \\
\hline Quercetin & $1.4-14.4$ & na & nd \\
Kaempferol & nd-20.0 & na & nd \\
Isorhamnetin & $4.5-30.0$ & 0.45 & nd -3.5 \\
Rutin & $2-20$ & na & nd-1.9 \\
Ginkgolide A & 242 & 165.17 & $0.92-3.47$ \\
Ginkgolide B & $388^{*}$ & 199.67 & $575-1988$ \\
Ginkgolide J & - & na & $15-47$ \\
Ginkgolide C & 143 & 136.3 & $152-600$ \\
Bilobalide & 122 & 72.52 & $22-46$ \\
Ginkgotoxin & 335 & na & na \\
Ginkgolic acid & 18 & 51.7 & $56.5-172.2$ \\
\hline
\end{tabular}

* Ginkgolide B and ginkgolide J are isomers and could not be separated upon the chromatographic conditions used; na-no data available; nd-not detected.

\subsection{Antimicrobial Studies}

Initially, the antimicrobial activity of Ginkgo seed extract was evaluated by the agar well diffusion method, which measures the diameter of the area around which the test agent has diffused, and inhibited germination and growth of the microbial strain tested. The highest applied concentration- $3.5 \mathrm{mg} / \mathrm{mL}$ for the time and conditions of incubation resulted in zones of inhibition between 0 and $13 \mathrm{~mm}$. No inhibition was caused by the control. Minimum inhibitory concentrations (MIC) of Ginkgo seed extract with respect to the microorganisms tested are shown in Table 5. 
Table 5. Minimum inhibitory concentrations (MIC, $\mathrm{mg} / \mathrm{mL}$ ) of $70 \%$ methanol extract from Ginkgo biloba kernels.

\begin{tabular}{cc}
\hline Strain & MIC \\
\hline Gram (+) bacteria & \\
Bacillus subtilis ATCC 6633 & 0.875 \\
Bacillus cereus & 0.875 \\
Bacillus amyloliquefaciens & 1.75 \\
Staphylococcus aureus ATCC 25923 & 0.875 \\
Listeria monocytogenes ATCC 8632 & - \\
Enterococcus faecalis & 3.5 \\
Micrococcus luteus & 3.5 \\
Gram (-) bacteria & \\
Salmonella enteritidis & 1.75 \\
Salmonella abony & - \\
Klebsiella sp. & - \\
Escherichia coli ATCC 8739 & 1.75 \\
Proteus vulgaris ATCC 6380 & - \\
Pseudomonas aeruginosa ATCC 9027 & 1.75 \\
Yeasts & \\
Candida albicans NBIMCC 74 & - \\
Saccharomyces cerevisiae & Fungi \\
Aspergillus niger ATCC 1015 & - \\
Aspergillus flavus & Penicillium sp. \\
Rhizopus sp. & 0.875 \\
Fusarium moniliforme ATCC 38932 & - \\
\hline & 1.75 \\
\hline & 0.109 \\
\hline
\end{tabular}

\section{Discussion}

Ginkgo biloba seeds have an advantage over the leaves in that they can not only be a source of phytochemicals, but also a source of macro-(proteins, fats, and carbohydrates) and micronutrients (trace elements, vitamins, amino acids, etc.). In this study, we quantified some constituents related to the nutritional value of Ginkgo kernels of Bulgarian origin. As the biosynthesis of plant primary and secondary metabolites shows significant variability due to the influence of population (location), season, climatic and agronomic factors, postcollection treatment, and other factors, we compared our findings with available data for other populations as well and with similar foods used in Bulgaria. Furthermore, we analyzed $70 \%$ methanol seed extract, which contains a significant proportion of polar and moderately polar secondary metabolites that are considered as principal carriers of the biological activity of plants.

Microelements are necessary for plant growth and development but also essential for humans. Most of them are part of enzymes; participate in antioxidant protection, metabolism of hormones, proteins, immune processes, etc. Plant food is a major supplier of these microelements. In the earth's crust, they are most often found as insoluble minerals; plants through their root system release organic compounds capable of chelating metal ions, bringing them into a soluble form that helps their movement between plant cells. In such soluble form, they are also delivered to humans through food intake.

The only available data for comparison regarding microelement content of seeds were those reported by Goh and Barlow [20]. They found $1.2 \mathrm{mg}$ iron per $100 \mathrm{~g}$ dry weight in nuts purchased from China, and those purchased from the US contained $1.4 \mathrm{mg} / 100 \mathrm{~g}$ (12-14 ppm), which is lower than the values we found.

The amount of protein in Ginkgo nuts was relatively low, given the significantly higher protein content of other nuts popular in Bulgaria: walnuts (26.1\%), peanuts $(25.8 \%)$, and almonds (21.9\%) [21]. Despite the low protein content, the proteins in Ginkgo biloba seeds seem to have other beneficial properties [17]. 
The fat content of seeds was much lower not only compared to other types of nuts (typically above $50 \%$ raw weight basis) but also compared to Ginkgo nuts originating in Korea: $2.2 \%$ on raw weight basis [22] or Massachusetts-USA: 3.75\% of dried nuts [23]. However, seed fat contains fatty acids, which are beneficial for humans, albeit in small amounts, and provide a good proportion of omega- 3 and omega- 6 fatty acids and tocopherols. This may explain the observation that the lipid fraction of Ginkgo seeds applied to an animal model was capable of modulating liver and serum apolipoproteins and cholesterol [23].

Starch, the reserve food for the embryo, was the constituent present in the largest amount in the seeds-about $70 \%$ of the dry matter. Due to the specificity of the enzymatic reaction, which always hydrolyzes the glycosidic bonds starting from the non-reducing end of the polysaccharide, the presence of significant amounts of amylose in the starch composition reduces the rate of glucose release. Thus, amylose content is an important but not the only factor influencing the rate of starch hydrolysis. The ratio of crystalline/amorphous parts of the polysaccharide, the degree of swelling, the length, folding, and number of branches of amylopectin also have an impact. Some of these factors also affect the enthalpy of gelling recorded by DSC. The amylose content of ginkgo seeds usually varies between $28.5 \%[24,25]$ and $33.2 \%$ [26]. The transition temperatures $\left(\mathrm{T}_{0}, \mathrm{~T}_{\mathrm{p}}\right.$, and $\left.\mathrm{T}_{\mathrm{c}}\right)$ of starches obtained from three Chinese Ginkgo cultivations [24] were close to those found for Ginkgo starch of Bulgarian origin. The high amylose content and high enthalpy of gelling of Ginkgo biloba starch were preliminary indicators that it may be more resistant to enzymatic hydrolysis than the other two starches studied. This assumption was confirmed by an in vitro study of its digestibility. The data obtained showed that Ginkgo biloba starch contains a smaller amount of digestible starch and a higher proportion of resistant starch compared to wheat and maize starch. A good negative correlation was found between the content of amylose and total digestible starch $(\mathrm{r}=-0.875)$ and a positive correlation between amylose and resistant starch $(\mathrm{r}=0.808)$, which confirms that the content of starch linear fraction is a significant factor in the degree of enzymatic hydrolysis of starch to glucose.

The flavonoids quercetin, kaempferol, and isorhamnetin and their glycosides represent about a quarter of the composition of the standardized Ginkgo biloba leaf extract EGb $761^{\circledR}$. In the extract of Ginkgo kernels, they are in significantly lower amounts. Although both aglycones and their glycosides have chromophores, we could not detect them by chromatographic separation with a UV detector. The quantification of the above-mentioned flavanols as free aglycones using LC-MS revealed that their content in the seed extract was indeed very low.

The unique constituents of Ginkgo biloba are the terpene trilactones, ginkgolides, and bilobalide. Specific beneficial effects of standardized leaf extract for patients with ischemic cardiovascular and cerebrovascular diseases are most often attributed to this class of bioactive constituents [27]. Our data from chromatographic analysis, as well as data from other authors, confirm that the terpene trilactones in seed extract are in greater quantities than flavonoids, and it could have healing properties similar to leaf extract. In a recent study, we confirmed that this extract enhances learning and memory functions in rats and has an effect comparable to that of the nootropic medication Piracetam [28].

Among the unfavorable components of the seed extract are ginkgotoxin (antivitamin $\mathrm{B}_{6}$ ) and ginkgolic acid. While the presence of ginkgotoxin in leaves is still uncertain, and perhaps is the reason why the European Pharmacopoeia does not set a limit for its content in the standardized leaf extract, the ginkgolic acid level is restricted in EGb 761 to 5 ppm because of allergenic and genotoxic effects. Some approaches to seed detoxification have recently been summarized [17]; for example, pre-cooking the seeds significantly reduces the amount of ginkgotoxin due to its good water solubility. In addition, our experiment showed that after further treatment of the aqueous methanolic extract with hexane, the level of ginkgolic acid was reduced from $19 \mathrm{ppm}$ to $4 \mathrm{ppm}$ with minor changes in the concentrations of other bioactive constituents. However, the pharmacological properties of ginkgolic acids family are not limited to those mentioned above [29] and undoubtedly deserve further research. 
Studies on the antimicrobial activity of seeds and their extracts are sporadic. Park and Cho have studied the antimicrobial properties of Ginkgo biloba leaf, seed, and seed coat extracts [30]. While leaf and seed coat extracts have shown very good antimicrobial activity, aqueous, methanol and ethanol seed extracts have proved to be inactive against the microorganisms tested. Based on an ancient Chinese recipe, Chassagne and colleagues have found that an $80 \%$ ethanol seed extract has been effective against pathogens involved in skin and soft tissue infections [31]. The authors attribute this antimicrobial activity to the presence of ginkgolic acid.

The extract obtained by cold maceration of Ginkgo seeds demonstrated weak antimicrobial activity against 13 of 20 tested microorganisms with MIC ranging from 0.109 to $1.75 \mathrm{mg} / \mathrm{mL}$. Gram-negative bacteria were less sensitive toward the constituents of extract, which is usually attributable to the permeability barrier posed by their outer membrane, which makes them more resistible to antimicrobial agents. The two yeasts tested were resistant to this extract. These antimicrobial properties might be more pronounced after removal of some constituents considered as inert, for example, carbohydrates, which constitute a significant part of the extract dry matter.

This study demonstrates that seeds of locally grown Ginkgo trees, that up to now have been considered an environmental pollutant, can be used as a source of biologically active substances. The chemical composition shows similarity to those of seeds from other geographical areas.

\section{Further Perspectives}

While the Ginkgo biloba tree is native to China and its nuts are used in Far Eastern national cuisines, in Bulgaria, Ginkgo seed is still unknown as food. The pursuit of healthy and organic eating has led to the entry of exotic - unknown until 10-20 years ago-foods into the country. Maybe it is time to promote Ginkgo seeds as well because they fully meet the definition of a functional food product, which in addition to providing nutrients and energy, favorable modulates one or more targeted functions in the body by enhancing a particular physiological response and/or reduce the risk of disease [32]. They can provide essential microelements, tocopherols, omega- 3 and omega- 6 fatty acids albeit in low concentrations, carbohydrates with low digestibility, high content of terpenoids (ginkgolides and bilobalide) with proven health benefits. These are all arguments in favor of the prospect of promoting Ginkgo seeds as healthy functional food. The limitation to this perspective is the content of ginkgotoxin and ginkgolic acid in nuts, so consumption of more than 10-20 nuts a day might pose health risks.

The other perspective is the separate use of detoxified organic seed extract, its standardization and use of its pharmacological potential as a nootropic agent, like the leaf extract, as well as purification of residual starch and its use in food and pharmaceutical industry. Both approaches could lead to a reduction of environmental pollution, better maintenance of park areas, utilization of this undoubtedly useful natural product, and potentially its future cultivation in Bulgaria.

Author Contributions: Conceptualization, T.T. and M.D.A.; formal analysis, D.T. and G.K.; data curation, I.S.; writing—original draft preparation, T.T. and I.S.; writing—review and editing, M.D.A.; project administration, M.D.A. All authors have read and agreed to the published version of the manuscript.

Funding: This work was supported by the Bulgarian Ministry of Education and Science (Grant D01-217/30.11.2018) under the National Research Programme "Innovative Low-Toxic Bioactive Systems for Precision Medicine (BioActiveMed)" approved by DCM \# 658/14.09.2018.

Institutional Review Board Statement: Not applicable.

Informed Consent Statement: Not applicable. 
Conflicts of Interest: The authors declare no conflict of interest. The funder had no role in the design of the study; in the collection, analyses, or interpretation of data; in the writing of the manuscript, or in the decision to publish the results.

\section{References}

1. DeFeudis, F.V.; Drieu, K. Ginkgo biloba extract (EGb 761) and CNS functions: Basic studies and clinical applications. Curr. Drug Targets 2000, 1, 25-58. [CrossRef]

2. Wieland, L.S.; Feinberg, T.M.; Ludeman, E.; Prasad, N.K.; Amri, H. Ginkgo biloba for cognitive impairment and dementia (Protocol). Cochrane Database Syst. Rev. 2002, 4, CD003120. [CrossRef]

3. Belwal, T.; Giri, L.; Bahukhandi, A.; Tariq, M.; Kewlani, P.; Bhatt, I.D.; Rawal, R.S. Chapter 3.19. Ginkgo biloba. In Nonvitamin and Nonmineral Nutritional Supplements; Nabavi, S.M., Silva, A.S., Eds.; Elsevier Inc.: Amsterdam, The Netherlands, 2019 ; pp. 241-250. [CrossRef]

4. Ivanova, V.; Natcheva, L.; Gercheva, P. Use of Ginko biloba, L. in green system of the town of Plovdiv. Sci. Works USB Plovdiv. Ser. C Tech. Technol. 2015, 13, 241-244.

5. American Oil Chemists Society (AOAC). Kjeldahl's method for protein determination in cereals and feed. In Official Methods of Analysis $^{S M}$, 16th ed.; Method 945; AOAC International: Rockville, MD, USA, 1996; p. 18-B.

6. International Organization for Standardization (ISO Standard No. 659:2009). Oilseeds—Determination of Oil Content (Reference Method); International Organization for Standardization: Geneva, Switzerland, 2009.

7. International Organization for Standardization (ISO Standard No. 5509:2000). Animal and Vegetable Fats and Oils. Preparation of Methyl Esters of Fatty Acids; International Organization for Standardization: Geneva, Switzerland, 2000.

8. International Organization for Standardization (ISO Standard No. 5508:2004). Animal and Vegetable Fats and Oils. Analysis by Gas Chromatography of Methyl Esters of Fatty Acids; International Organization for Standardization: Geneva, Switzerland, 2004.

9. International Organization for Standardization (ISO Standard No. ISO 9936). Animal and Vegetable Fats and Oils. Determination of Tocopherols and Tocotrienols Contents. Method Using High-Performance Liquid Chromatography; International Organization for Standardization: Geneva, Switzerland, 2006.

10. Knutson, C.A.; Grove, M.J. Rapid Method for Estimation of Amylose in Maize Starches. Cereal Chem. 1994, 71, 469-471.

11. Morado-Castillo, R.; Quintanilla-Licea, R.; Gomez-Flores, R.; Blaschek, W. Total Phenolic and Flavonoid Contents and Flavonoid Composition of Flowers and Leaves from the Mexican Medicinal Plant Gymnosperma glutinosum (Spreng.) Less. Eur. J. Med. Plants 2016, 15, 1-8. [CrossRef]

12. Hagerman, A.E.; Butler, L.G. Protein precipitation method for the quantitative determination of tannins. J. Agric. Food Chem. 1978, 26, 809-812. [CrossRef]

13. Haldar, D.; Sen, D.; Gayen, K. Development of Spectrophotometric Method for the Analysis of Multi-component Carbohydrate Mixture of Different Moieties. Appl. Biochem. Biotechnol. 2017, 181, 1416-1434. [CrossRef] [PubMed]

14. Ivanov, I.G.; Vrancheva, R.Z.; Marchev, A.S.; Petkova, N.T.; Aneva, I.Y.; Denev, P.P.; Georgiev, V.G.; Pavlov, A.I. Antioxidant activities and phenolic compounds in Bulgarian Fumaria species. Int. J. Curr. Microbiol. App. Sci. 2014, 3, $296-306$.

15. Feodorova, Y.; Tomova, T.; Minchev, D.; Turiyski, V.; Draganov, M.; Argirova, M. Cytotoxic effect of Ginkgo biloba kernel extract on HCT116 and A2058 cancer cell lines. Heliyon 2020, 6, e04941. [CrossRef]

16. Tumbarski, Y.; Lincheva, V.; Petkova, N.; Nikolova, R.; Vrancheva, R.; Ivanov, I. Antimicrobial activity of extract from aerial parts of potentilla (Potentilla reptans L.). Ind. Technol. 2017, 4, 37-43.

17. Wang, H.-Y.; Zhang, Y.-Q. The main active constituents and detoxification process of Ginkgo biloba seeds and their potential use in functional health foods. J. Food Comp. Anal. 2019, 83, 103247. [CrossRef]

18. Zhou, G.; Yao, X.; Tang, Y.; Qian, D.; Su, S.; Zhang, L.; Jin, C.; Qin, Y.; Duan, J. An optimized ultrasound-assisted extraction and simultaneous quantification of 26 characteristic components with four structure types in functional foods from ginkgo seeds. Food Chem. 2014, 158, 177-185. [CrossRef]

19. Chen, X.; Zhong, W.; Shu, C.; Yang, H.; Li, E. Comparative analysis of chemical constituents and bioactivities of the extracts from leaves, seed coats and embryoids of Ginkgo biloba L. Nat. Prod. Res. 2020, 35, 1-4. [CrossRef]

20. Goh, L.M.; Barlow, P.J. Antioxidant capacity in Ginkgo biloba. Food Res. Int. 2002, 35, 815-820. [CrossRef]

21. Brufau, G.; Boatella, J.; Rafecas, M. Nuts: Source of energy and macronutrients. Br. J. Nutr. 2006, 96, 24-28. [CrossRef] [PubMed]

22. Hierro, M.T.G.; Robertson, G.; Christie, W.W.; Joh, Y.-G. The fatty acid composition of the seeds of Ginkgo biloba. J. Am. Oil Chem. Soc. 1996, 73, 575-579. [CrossRef]

23. Mahadevan, S.; Park, Y.; Park, Y. Modulation of cholesterol metabolism by Ginkgo biloba L. nuts and their extract. Food Res. Int. 2008, 41, 89-95. [CrossRef]

24. Miao, M.; Jiang, H.; Jiang, B.; Cui, S.W.; Jin, Z.; Zhang, T. Structure and functional properties of starches from Chinese ginkgo (Ginkgo biloba L.) nuts. Food Res. Int. 2012, 49, 303-310. [CrossRef]

25. Cai, J.; Cai, C.; Man, J.; Xu, B.; Wei, C. Physicochemical Properties of Ginkgo Kernel Starch. Int. J. Food Prop. 2015, 18, 380-391. [CrossRef]

26. Zheng, Y.; Zhan, H.; Yao, C.; Hu, L.; Peng, Y.; Shen, J. Study on physicochemical and in-vitro enzymatic hydrolysis properties of ginkgo (Ginkgo biloba) starch. Food Hydrocoll. 2015, 48, 312-319. [CrossRef] 
27. Liu, X.-W.; Yang, J.-L.; Niu, W.; Jia, W.-W.; Olaleye, O.E.; Wen, Q.; Duan, X.-N.; Huang, Y.-H.; Wang, F.-Q.; Du, F.-F.; et al. Human pharmacokinetics of ginkgo terpene lactones and impact of carboxylation in blood on their platelet-activating factor antagonistic activity. Acta Pharmacol. Sin. 2018, 39, 1935-1946. [CrossRef] [PubMed]

28. Tomova, T.; Doncheva, N.; Mihaylova, A.; Kostadinov, I.; Peychev, L.; Argirova, M. An Experimental Study on Phytochemical Composition and Memory Enhancing Effect of Ginkgo biloba Seed Extract. Folia Med. 2021, 63, 203-212. [CrossRef] [PubMed]

29. Gerstmeier, J.; Seegers, J.; Witt, F.; Waltenberger, B.; Temml, V.; Rollinger, J.M.; Stuppner, H.; Koeberle, A.; Schuster, D.; Werz, O. Ginkgolic Acid is a Multi-Target Inhibitor of Key Enzymes in Pro-Inflammatory Lipid Mediator Biosynthesis. Front Pharmacol. 2019, 10, 797. [CrossRef] [PubMed]

30. Park, S.-B.; Cho, G.-S. Antimicrobial Activity of Extracts and Fractions of Ginkgo biloba Leaves, Seed and Outer Seedcoat. J. Korean Soc. Food Sci. Nutr. 2011, 40,7-13. [CrossRef]

31. Chassagne, F.; Huang, X.; Lyles, J.T.; Quave, C.L. Validation of a 16th Century Traditional Chinese Medicine Use of Ginkgo biloba as a Topical Antimicrobial. Front. Microbiol. 2019, 10, 775. [CrossRef]

32. Bigliardi, B.; Galati, F. Innovation trends in the food industry: The case of functional foods. Trends Food Sci. Technol. 2013, 31, 118-129. [CrossRef] 